\title{
Unpacking the Complexity of Consistency: Insights from a Grounded Theory Study of the Effective Use of Electronic Medical Records
}

\author{
Rebekah Eden \\ UQ Business School \\ The University of Queensland \\ St. Lucia, QLD 4072, Australia \\ r.eden@busines.uq.edu.au \\ Andrew Staib \\ Princess Alexandra Hospital \\ Metro South Health \\ MMRI University of Queensland \\ Translational Research Institute \\ QLD 4102, Australia \\ andrew.staib@health.qld.gov.au
}

\author{
Saeed Akhlaghpour \\ UQ Business School \\ The University of Queensland \\ St. Lucia, QLD 4072, Australia \\ s.akhlaghpour@business.uq.edu.au
}

\author{
Clair Sullivan \\ Princess Alexandra Hospital \\ Metro South Health \\ MMRI University of Queensland \\ Translational Research Institute \\ QLD 4102, Australia \\ clair.sullivan@health.qld.gov.au
}

\author{
Paul Spee \\ UQ Business School \\ The University of Queensland \\ St. Lucia, QLD 4072, Australia \\ p.spee@business.uq.edu.au
}

Andrew Burton-Jones

UQ Business School and Centre for

Business and Economics of Health,

The University of Queensland

St. Lucia, QLD 4072, Australia

abj@business.uq.edu.au

\begin{abstract}
We examined what it takes to use an electronic medical record system effectively in a large acute care hospital. As our findings emerged, the value and complexity of consistency in use became salient. At our site, consistency in use had five interrelated dimensions (process, meaning, form, place, content) with multiple different consequences. From a theoretical perspective, our findings suggest the need for more research at the intersection of system design and user practices on how inconsistencies should be conceptualized, what causes them, and how they should be addressed. From a practical perspective, the insights help explain the difficulty of achieving effective use and provide insights for improving it.
\end{abstract}

\section{Introduction}

What does it take to use an organizational information system effectively? Although much is known about how to get individuals to use information systems more (rather than less) [15, 32, 33], researchers have begun shifting attention to the lessstudied topic of what it takes to use them effectively [1, $3,19,28]$, where effective use is that type of use that helps obtain desired goals [4]. Given the nascent stage of research on this topic, we took a grounded theory approach to address the question. We focused, in particular, on learning about effective use in the context of an electronic medical record (EMR) system in a large acute care hospital, as this is a context in which effective use is highly relevant $[16,26]$.
Following the grounded theory approach [13], we began with an open mind regarding what effective use involved. A recurring theme in our data, however, was the inconsistencies in use amongst staff. Because this issue was so salient, we narrowed our focus from the overall issue of effective use to the specific issue of inconsistencies in use. Our research questions became: 1) What is the nature of consistency or inconsistency in use? 2) Why is consistency in use important? We seek to contribute by answering these questions and outlining new questions that arose through our study.

We propose that consistency in use is a potentially important topic because it relates so intimately to the nature of both information systems and practices.

From an information systems perspective, consistency is closely tied to the nature of information systems. For instance, any relational database assumes consistency in the way entities and their properties are defined [21]. And a major reason many organizations implement information systems is to increase consistency, by enforcing work practices [6] and using standardized data to monitor practices [17].

From a practice perspective, consistency and reliability in performance are intimately tied to questions of standardization and craft [27]. In healthcare, in particular, there have often been calls for greater consistency in care and documentation practices $[34,37]$ but concerns over the right balance of standardization and craft are said to "cut to the heart of what it means to be a physician" [14 p. 836].

We searched for papers on consistency in use in Information Systems and Health Informatics journals and found several papers mentioning it, but none studying it in detail. In Health Informatics, several 
studies noted how EMR systems are often implemented to help achieve greater consistency in practice, but they can also create new types of inconsistencies [18, 23, 25]. In Information Systems, three recent studies note the importance of consistency in use, showing how some affordances of information systems do not arise unless workers act on prerequisite affordances consistently (e.g., reports may not work if data is not entered consistently) [5, 20, 31].

In the studies we reviewed, consistency was viewed simply, e.g., as a single dimension [20, 31] or with independent dimensions [5]. This contrasted with our data that showed that consistency in use was complex, with multiple interrelated dimensions (as discussed later). Motivated by these findings, as well as recent calls to unpack the related concept of standardization [36], we sought to understand the issue in more depth.

In summary, an examination of consistency in use should offer practical insights for understanding the effective use of information systems, and potentially also for reaching a deeper understanding of the nature of information systems and work practices, particularly in healthcare. In the next sections, we outline our grounded theory methods for studying the issue, our findings, and implications for research and practice.

\section{Grounded Theory Case Study}

In this research, we used a case study approach and applied the grounded theory methodology [11] largely following the procedure outlined by Fernandez [10].

The case organization is a large public acute care hospital in Australia, with over 6,000 staff, and over 150,000 admissions and 0.5M outpatient appointments per year. As part of a state-wide government initiative to improve care and increase efficiencies in the state's hospitals, the case organization became the lead site to implement a hospital-wide EMR. The EMR has been used by the hospital for 1.5 years. The implementation occurred in two releases: the first in late 2015 focused on documentation and orders and the second in early 2017 focused on medications, anesthetics, and trials.

Following grounded theory methods [7, 10], we entered the field site with a broad aim, to understand the effective use of the EMR. We relied principally on interviews, supplemented with focus groups and analysis of documentation. The interviews and focus groups took place over four months and occurred before (Phase 1) and after (Phase 2) the second release (known as the MAR). We selected participants as our understanding of the situation developed. For example, we determined a mixture of frontline nurses, doctors, pharmacists, allied health professionals and executive management should be interviewed to allow for constant comparisons, a central tenet of grounded theory [12], but over time we learned that use also varied in important ways across other units (such as the Emergency Dept.) and roles (such as administration), so we sampled further in these areas. In total, 91 individuals participated, most of them (64) in both phases, with the remaining 27 in only one phase (i.e. 11 participants in phase 1 only; 16 in phase 2 only).

Table 1 provides an overview of the participants in interviews and focus groups. All interviews and focus groups were recorded, transcribed, and uploaded in NVivo. Acknowledging the concerns of [12], we used NVivo as an electronic repository only and manually performed coding and memoing. In line with the nonpositivist nature of grounded theory $[11,13]$, we did not use independent coders but instead coded the data ourselves and validated it through dialog amongst the research team and with clinicians at the site. Initially, we used open coding to identify concepts in our data and did not have a "preconceived set of codes" [10]. The core concept of consistency (or inconsistency), emerged as being critical, leading us to look more closely at both our data and related literature.

Table 1: Overview of research participants

\begin{tabular}{|l|l|l|l|}
\hline & \multicolumn{3}{|c|}{ Number of Participants* } \\
\hline Front Line Clinicians & Phase 1 & Phase 2 & Overall \\
\hline$\bullet \quad$ Allied Health & 11 & 10 & 11 \\
\hline$\bullet \quad$ Doctors & 15 & 14 & 17 \\
\hline$\bullet \quad$ Nurses & 17 & 16 & 21 \\
\hline$\bullet \quad$ Pharmacists & 3 & 3 & 3 \\
\hline Management & & & \\
\hline$\bullet \quad$ Administration & 5 & 8 & 8 \\
\hline$\bullet \quad$ Executive & 17 & 17 & 17 \\
\hline$\bullet \quad$ Other & 9 & 12 & 14 \\
\hline Total & 76 & 80 & 91 \\
\hline \\
participants (e.g., the same pharmacists participated in phase \\
1 and 2, hence the number of unique pharmacists is 3).
\end{tabular}

We began with a working definition of consistency, simply reflecting a lack of variability in types of use. However, we needed a more precise definition so that we could focus on variations not designed or expected a priori (e.g., differences in use between a nurse and a doctor might reflect expected differences in roles, but differences between two nurses in the same ward might reflect true inconsistencies). Drawing on the analysis of consistency in [5], we defined consistency in our data as the lack of variation among instances of use of a given type, where a type is characterized by specific attributes, such as a unit, profession, or demographics. As we collected our data, we were frequently told that the problems caused by such inconsistencies were potentially important: 
"With triage, there is a very high risk of human error [like] wrong patient identification, charting in the wrong... medical records... So that's... why we need... consistency... to prevent risk." (Director of Nursing A, Phase 1)

"[There are] inconsistencies in ED. And I think it's the system itself. There's five different ways to do one thing. ...We've had a lot of issues with inconsistencies [and] ...it does affect all our data reporting as well. So that has become quite a big issue for us." (Director of Nursing A, Phase 2)

"I started to look for information and [couldn't find it] but I'm not a user every day ... So I went to [the] users and they [said], 'Well, actually there's nothing documented,' or 'there was no consistency [in what is documented].' ...[Then the head nurse] hosted a focus group for the hospital ...The issue is we are very good at following rules, but there are not enough rules."

(Director of Nursing B, Phase 1).

We then on-coded the inconsistency concept by constantly comparing the different consistency quotes [11] and identified five types of inconsistency, detailed in the next section. Subsequently, during theoretical coding, we identified their consequences and identified interdependencies among the different types of inconsistency. We continued oncoding until theoretical saturation was reached, i.e., whereby no new types of consistency or relationships emerged [13].

\section{Findings}

We first present insights into the nature of inconsistency in use, followed by its consequences.

\subsection{Nature of Inconsistency in Use}

We focus on inconsistency in use because while consistency emerged as a core concept in our data, we found that participants talked about the concept more in terms of its converse, just as in prior studies of fit and misfit [30]. As shown in Table 2, we identified five main types of inconsistency in our data: content, form, meaning, place, process.

We also identified interdependencies among these types of inconsistency, as shown in Figure 1. Inconsistencies in meaning and process appeared to affect inconsistencies in form and place. Inconsistencies in process, form, and place then led to inconsistency in content. These interrelationships underscore complexity of the problem. For instance, to resolve issues with inconsistencies in content, one needs to consider not just that problem but all the prior types of inconsistency that may be causing it too. Likewise, if an organization only tried to resolve inconsistency in process, inconsistencies in meaning, place, form and content could still cause issues.

Table 3 provides evidence for the interdependencies shown in Figure 1. In Table 3 and Figure 1, we show these interdependencies in a one-toone manner for simplicity. But this should not be read as implying that the links only occurred one at a time, because the problem was more complex than this. In any given occurrence, multiple links could be present at once. For example, we found inconsistencies in meaning, place, and content could all appear in a single occurrence (as in the instance of 'weight', which was recorded in different places, with different meanings, and resulted in nurses seeing different content):

Table 2: Types of inconsistency

\begin{tabular}{|c|c|c|}
\hline $\begin{array}{c}\text { Inconsistency } \\
\text { Type } \\
\end{array}$ & Definition & Example Quotes \\
\hline Content & $\begin{array}{l}\text { Variations in the } \\
\text { completeness and } \\
\text { accuracy of data } \\
\text { within the EMR }\end{array}$ & $\begin{array}{l}\text { We insist that the doctors who make notes, make sure that everything that is } \\
\text { included in that visit is included in their notes. And what we struggle with } \\
\text { sometimes is that some of the [doctor] investigators are very good at } \\
\text { documentation, others not... So, it's finding that consistency in practice to make } \\
\text { sure that the information is consistent and concise. (Trial Coordinator, Phase 1) }\end{array}$ \\
\hline Form & $\begin{array}{l}\text { Variations in the } \\
\text { structure of the } \\
\text { data within the } \\
\text { EMR }\end{array}$ & $\begin{array}{l}\text { I think people find something that works for them and they just use it. So, for } \\
\text { example, templates for various ward rounds or outpatients or whatever. Some } \\
\text { are quite sophisticated in how they do that and others just use the same blank } \\
\text { document for every single thing. (Senior Doctor, Phase 1) }\end{array}$ \\
\hline Meaning & $\begin{array}{l}\text { Variations in how } \\
\text { individuals } \\
\text { interpret the fields } \\
\text { or content present } \\
\text { within the EMR }\end{array}$ & $\begin{array}{l}\text { It's that an order in the MAR is for blood. There are some conditions for which } \\
\text { the preference would be to use blood products rather than whole blood. Say, for } \\
\text { example, cryoprecipitate for example. But what I think maybe our doctors are } \\
\text { seeing is an order in that space would also include blood products; it doesn't. } \\
\text { (Senior Executive, Phase 2) }\end{array}$ \\
\hline
\end{tabular}




\begin{tabular}{|l|l|l|}
\hline Place & $\begin{array}{l}\text { Variations in } \\
\text { where clinicians } \\
\text { input and find data } \\
\text { within the EMR }\end{array}$ & $\begin{array}{l}\text { It feels very substandard where people document things ... You might come to } \\
\text { ward 6A and you look at your progress notes and go wow, this ward doesn't } \\
\text { document at all. You go into assessments and results and it's actually a really } \\
\text { thorough assessment but they don't know to access that. (Nurse, Phase 1) }\end{array}$ \\
\hline Process & $\begin{array}{l}\text { Variations in how } \\
\text { clinicians embed } \\
\text { the EMR into their } \\
\text { work practices }\end{array}$ & $\begin{array}{l}\text { What we're doing hasn't been told to us, so like you'll sit on the ward and you'll } \\
\text { go, "Oh, how do I do this?" and someone will go, "Oh, you didn't need to do } \\
\text { that." And someone else will go, "Yeah, you have to do that." "Oh no, they told } \\
\text { me you didn't have to do that." Yeah. So I'm just like trying to do the best that I } \\
\text { can do and do what I think is right, but also do what we were told to do. } \\
\text { (Pharmacist, Phase 2) }\end{array}$ \\
\hline
\end{tabular}

"There's two fields - ...estimated weight and ...measured weight. If you put it in the estimated, even though you've measured it, for the doctors that doesn't pull across to them then. It's only when it's measured weight. So they do a lot of medications titrations off weight. So if that doesn't pull across, then the nurse has got to get on and oh hang on a minute, they were weighed this morning" (Nurse Unit Manager, Phase 1)

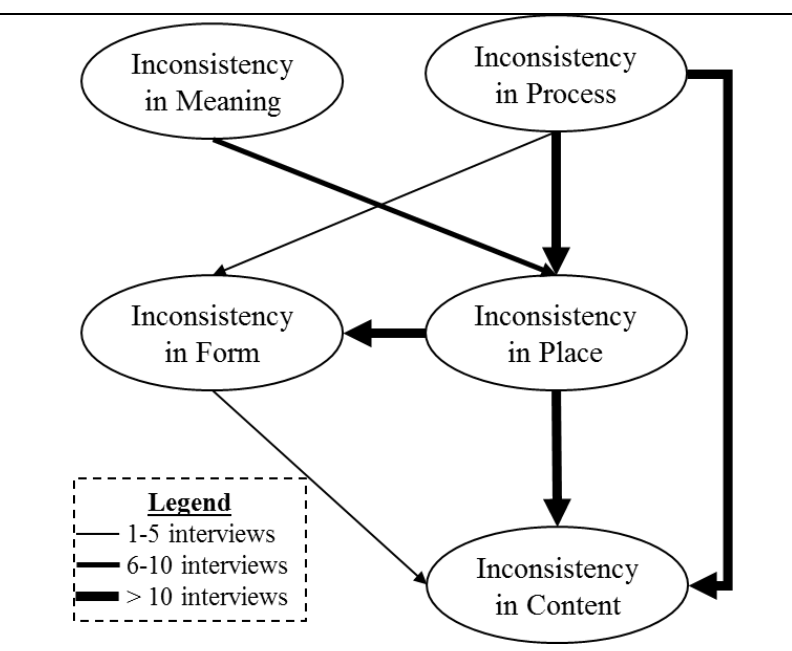

Key: Thickness of lines indicates the number of interviewees who referred to the interdependency (where thicker is more)

Figure 1: Interdependencies among inconsistencies ${ }^{1}$

We also saw examples where inconsistencies in process, place, and form, as well as process, place and content existed respectively, as in these examples:

"99\% of our staff have ...knowledge to use it very well. Are we using it to the highest capacity it can be? No. ...Things [are] getting missed, because ...each unit has their own way of doing things. ...We're supposed to be opening a care plan and

${ }^{1}$ We recognise the limitations of counts in qualitative research [24], but include them in Figure 1 as we found them useful in depicting the prevalence of the interdependencies apparent in our data. making sure ...variances have been attended to by clicking the [checkboxes], but it's getting missed... Other wards are not doing the care plan.... They're doing the documentation... but each ward's got their own way of what they're doing and it starts a bit of confusion." (Nurse, Phase 1)

"There are a number of ways that a clinician can assess the patient [e.g. pressure injuries, wound management] and not complete all components, so we have a situation where a clinician can come in through this door and do this amount, but not this bit. A person can come from the top door and do it all. Somebody else might come in from this door and only do their little bit. (Director of Nursing, Phase 1)

\subsection{Consequences of Inconsistency}

As noted earlier, inconsistency pertains to variations among instances of use of a given type [5]. In principle, this suggests two types of inconsistency.

The first type occurs when instances vary in quality; we call this type 'specific.' In such a case, the existence of inconsistency directly implies variation in consequences, i.e. an effective or ineffective outcome.

The second type can occur irrespective of variation in the quality of the instances and instead occurs due to the combination of the instances. For instance, if two therapists enter the same type of data in two places that seem equally appropriate, a report that pulls the data from only one place may not work. In this case, the instances themselves did not appear specifically to have negative consequences but the combination did. This implies five types of inconsistency:

- Specific effective: Where positive consequences arise due to the occurrence of higher quality instances (e.g. a nurse may perform a task differently to others, and this may improve care)

- Specific ineffective: Where negative consequences arise due to the occurrence of lower quality instances (e.g., some nurses may enter data less accurately than others, impairing care) 
- Combination benign: Where no negative or positive consequences arise due to differences among instances, regardless of differences in the quality of those instances (e.g., some nurses may write notes differently to others, but these differences may be acceptable in that context)

- Combination effective: Where positive consequences arise due to differences among the instances regardless of differences in the quality of instances (e.g., some nurses may interact with the EMR differently, triggering insights that lead to innovative work practices)

- Combination ineffective: Where negative consequences arise due to differences among the instances, regardless of differences in the quality of instances (e.g., some nurses may enter data in different fields, all of which appear reasonable, but reports may be inaccurate because they extract data from just one of these fields).

Table 3: Independencies among inconsistency types

\begin{tabular}{|c|c|}
\hline $\begin{array}{l}\text { Interdependency } \\
\text { of Inconsistency }\end{array}$ & Example Quotes \\
\hline $\begin{array}{l}\text { Meaning } \rightarrow \\
\text { Place }\end{array}$ & $\begin{array}{l}\text { As doctors we just kind of ignored the encounters, we thought they were something just purely to } \\
\text { do with billings and disregarded them which I think we were probably told to do initially but then } \\
\text { subsequently [realised] that it is actually really important. Because I've had notes that have been } \\
\text { marked in error by other people because I'd done it in the wrong encounter ... So now I'm really } \\
\text { careful about using the right encounter. (Consultant, Phase 2) }\end{array}$ \\
\hline Process $\rightarrow$ Form & $\begin{array}{l}\text { Part of that is actually having efficient ways to write the note. So, having templates ... where you } \\
\text { can set up the ward ... have things ready to go and then as you're doing the round, follow the little } \\
\text { bits that you have time for and then save a note, whereas a lot of teams I find aren't doing that and } \\
\text { [instead] doing a quick round and sitting down at the end, writing a note out which is not ideal, } \\
\text { you know. (Clinical Pharmacologist, Phase 1) }\end{array}$ \\
\hline Process $\rightarrow$ Place & $\begin{array}{l}\text { When it's 'make up what you feel is suitable for your area' it doesn't work when you've got a large } \\
\text { hospital and inter-ward transfers and stuff like that. You might be doing it totally differently to } \\
\text { how other wards are documenting. Some wards are documenting just in progress notes, they're not } \\
\text { utilizing the system to its fullest. (Nurse, Phase 1) }\end{array}$ \\
\hline $\begin{array}{l}\text { Process } \rightarrow \\
\text { Content }\end{array}$ & $\begin{array}{l}\text { Within pharmacy everyone's doing a lot of things differently. ... [For example] we need to [use } \\
\text { PVnet, a separate system,] and individually verify every ....medication order... Not everyone does } \\
\text { that because not everyone feels that it's necessary, even though at a high level it was... So then } \\
\text { it's not like they half use it, they just, "No, I'm not using it." So... someone comes to your ward } \\
\text { and they haven't used PVnet so then you think that all the orders are unverified but it's maybe } \\
\text { because the individuals where they came from just doesn't do it, so you don't know whether or } \\
\text { not they're being screened properly or they just didn't want to verify it. (Pharmacist, Phase 2) }\end{array}$ \\
\hline Place $\rightarrow$ Form & $\begin{array}{l}\text { You can go in the quick view and it's got a whole lot of different bars and you... just tick through } \\
\text { it. However, our nurse unit manager... said 'the expectation is that you will document properly in } \\
\text { a progress note as well'....If you've done all your ticking and flicking in 'quick view' and... you } \\
\text { go into... your progress notes, you're writing the same thing that you've already clicked through. } \\
\text {... Some people do ticking and flicking, some do progress notes; some do both. (Nurse, Phase 1) }\end{array}$ \\
\hline $\begin{array}{l}\text { Place } \rightarrow \\
\text { Content }\end{array}$ & $\begin{array}{l}\text { [Care plans are] just so laborious for the staff to do it the way it's on the system... so it's only } \\
\text { partially getting done by some staff, it's not always getting completed.... Well when you've got to } \\
\text { repeat yourself, you know, sometimes you'll get it written here, but you won't get it written here... } \\
\text { (Nurse Unit Manager, Phase 1) }\end{array}$ \\
\hline $\begin{array}{l}\text { Form } \rightarrow \\
\text { Content }\end{array}$ & $\begin{array}{l}\text { Normally, more junior staff have... longer more detailed entries, ... whereas the more senior you } \\
\text { go the entries get shorter and shorter, and they just focus on the more important details, so I prefer } \\
\text { to get the ones from the juniors because they basically write your admission note for you, whereas } \\
\text { the seniors, for example, someone with a cut on your hand, the senior would just be like, 'cut on } \\
\text { hand', and just put a little bit of the examination to show that all fingers are working properly, and } \\
\text { then just say, referred to whatever, waiting. And then there is the juniors who will normally write } \\
\text { the whole thing, their background, ....allergies, ... regular medications [etc.]. (Resident, Phase 1) }\end{array}$ \\
\hline
\end{tabular}

Even though all five types may exist in principle, the consequences of inconsistency that were benign and effective were seldom observed in our data. We did not observe any occasion of 'specific effective' 
consequences. In terms of 'combination effective,' some participants highlighted that inconsistencies could lead to innovative practices:

"I would say that variation is okay. I don't think one size fits all, and I don't think that you can standardize everything across divisions. I think that's something I've learned. I did believe that we should be doing things the same way when I first came here, but actually... sometimes that [variation] is what leads you to innovation." (Director of Nursing C, Phase 2).

Others highlighted "the art of medicine, as opposed to the science" (Executive management, Phase 2), with too much consistency leading to recipe-based medicine, which could decrease the clinician's skills:

"We want our clinicians to look at ways of optimizing the EMR ...because that's where we encourage this innovation. There's more than one way to run a busy ...ward and we've got some great nurse unit managers. Each have their own flavor. They don't do it exactly the same as per the recipe book but they all get the same really good results. ...We need to have [that variation], otherwise I think we risk dumbing the [medical] system down and you don't need highlevel clinicians. You can just get anyone off the street to deliver this care because the computer says yes or no." (Director of Nursing D, Phase 2)

Inconsistencies that resulted from 'combination benign' instances largely reflected that clinicians have different preferences in how they structure their notes, with individuals identifying that as long as the required content is present they are not too concerned about the structure:

"I found them both, in a way are [equally effective], ...most people ...use the blank form, but ...others, especially the outpatients, ...use the doctors view part. But I think they can be equally [effective], because the important thing is all of them have the impression and the plan, and the main findings" (Registrar, Phase 2).

Whilst consequences stemming from 'combination benign' and 'combination effective' were apparent in the data, the presence of 'specific ineffective' and 'combination ineffective' were far more prevalent. Following the guidelines of grounded theory [13], we therefore explored these in greater depth, the findings of which are reported herein.
For inconsistency in process, consequences stemmed largely from 'specific ineffective' and 'combination ineffective' instances. For example, even though the EMR was mandatory to use, some clinicians refused to use it, whilst others used the EMR to varying degrees. The non-use of the EMR is an ineffective instance because it negatively affected others (e.g. clinicians, administrative officers):

"A surgeon has refused to [use the EMR] and writes her notes on pieces of papers, so the nurses are running around grabbing it and putting labels on it and sending it for scanning. So it is not even sitting in the right place in the record." (Admin. Manager, Phase 1)

Moreover, consequences for inconsistency in process also stemmed from presence of 'combination ineffective' instances:

"Probably the biggest thing is that [in the EMR] there are 20 different ways to do things. And 20 different things are still correct. It just means it creates more confusion." (Nurse, Phase 1)

Appendix 1 provides a summary of the consequences of each of the types of inconsistencies and whether they resulted from 'specific ineffective,' or 'combination ineffective' variations.

\section{Discussion and Conclusion}

As we noted earlier, consistency was very salient in our case data. We also noted the shortcomings of existing conceptualizations of consistency. We now revisit our research questions. First, what is the nature of consistency or inconsistency in use? Our data suggest that consistency is a more complex construct than previously recognized. In our data, inconsistencies were reflected in five dimensions with complex interrelationships. This contrasts with a simplistic view in past research $[5,20,31]$. We surmise that it might be this complexity that made the problem so salient and difficult to address at our site.

An interesting aspect of our findings is that the dimensions we found (process, meaning, form, place, content) were similar to those in [5] (utilization, meaning, form, place, amount). As the findings in [5] were also from healthcare (in that case, community care rather than a hospital), it suggests that there may be underlying issues with health records or care practices that trigger these inconsistencies rather than just being isolated case findings. However, unlike [5], we found evidence that these dimensions were strongly interrelated. Our findings also suggest it may 
be valuable to revisit early work, which usefully examined how consistency related to other dimensions of data quality [29, 35].

A final response to our first question relates to its definition (i.e. variation among instances of a given type). The more we analyzed our data, the more we saw that perceptions of inconsistency are complex because clinicians engage in so many types of use (due to their multiple roles and variety of patients) and subjective because clinicians may view these types of use differently because they view their work differently. This implies that the problem of inconsistencies needs to be tackled at least in part by recognizing these subjectivities [8]. For example, clinicians could be encouraged to see how inconsistencies stem from differences in users' understanding of their work and engage in reflection and perspective-taking to consider why these understandings exist and who may bear their effects.

Second, why is consistency in use important? Our data suggest that inconsistencies in use lead to a wide variety of negative consequences, as shown in the Appendix. As we noted earlier, they could also, in principle, lead to positive consequences, but this did not come through strongly in our data. The important issue to highlight from the Appendix is the number and variety of consequences that ensue. The variety stems from the different causes (whether due to a specific instance or a combination of instances) and from the different outcomes (in terms of confusion, impaired care, and lost time).

Finally, our study also raises new questions providing the basis for future research. For instance, can the ideas here be extended or refined by using existing organizational theories? Routines theory might provide a promising lens for studying these diverse variations of EMR use in practice. In this perspective, organizations are conceptualized as bundles of routines, i.e., "repetitive, recognizable pattern[s] of interdependent actions, involving multiple actors" [9 p. 96]. Recent research has uncovered the arguably surprising presence of variation and inconsistency in what would typically be perceived as stable routines [9, 27]. For example, in studying routines in reinsurance, [27] showed how the same routine can be differently oriented as it is enacted ad-hoc by skillful professionals in different parts of the appraisal task. Our analysis could potentially be extended with such an approach.

Another complementary theoretical lens is paradox. The issue of consistency might be labeled a paradox because the most effective use of an information system might involve both consistency and inconsistency. For instance, the hospital might benefit from improving consistency in medical records and patient care, but the nature of effective clinical work also necessitates inconsistencies in practice. The challenge is finding the warranted level of consistency - along the five dimensions identified in this study. As a first step to address the paradox, we followed [22]'s suggestion by unpacking the complexity of (in)consistency and developing a novel conception of it based on the case data. Nonetheless, future researchers can take the paradox lens further because it can be a powerful tool for theorizing [22].

More generally, identifying types of inconsistency and their interdependencies provides a new analytical tool for research. We know mutual adaptations between information systems and organizational routines are necessary following large system implementations [2]. Future research can use our analysis to help practitioners to understand the links between different types of inconsistency and different domains of misfit [30] and mitigate the risks.

\section{Acknowledgments}

The authors acknowledge support from Metro South Health, and ARC FT130100942 (to the final author).

\section{References}

[1] Bagayogo, F.F., L. Lapointe, and G. Bassellier, Enhanced Use of IT: A New Perspective on Post Adoption, Journal of the Association for Information Systems, 15(7), 2014, pp. 361-387.

[2] Berente, N., K. Lyytinen, Y. Yoo, and J.L. King, Routines as Shock Absorbers During Organizational Transformation: Integration, Control, and NASA's Enterprise Information System, Organization Science, 27(3), 2016, pp. 551-572.

[3] Burton-Jones, A., M. Bremhorst, F. Liu, and T.V.-H. Trieu, IT Use: Notes on a Journey from Use to Effective Use, in The Routledge Companion to Management Information Systems, R. Galliers and M.-K. Stein, Editors, Routledge: Abingdon, Oxon, 2017.

[4] Burton-Jones, A. and C. Grange, From Use to Effective Use: A Representation Theory Perspective, Information Systems Research, 24(3), 2013, pp. 632-658.

[5] Burton-Jones, A. and O. Volkoff, What Does it Mean to use an Organizational Information System Effectively? Insights from Users of a Community Care Electronic Health Record System, Information Systems Research, forthcoming, 2017.

[6] Davenport, T.H., Putting the Enterprise into the Enterprise System, Harvard Business Review, July/August, 1998, pp. 1-10.

[7] Eisenhardt, K.M., Building Theories from Case Study Research, Academy of Management Review, 14(4), 1989, pp. 532-550.

[8] Ellingsen, G., E. Monteiro, and G. Munkvold, Standardization of Work: Co-constructed Practice, The Information Society, 23(5), 2007, pp. 309-326. 
[9] Feldman, M.S. and B.T. Pentland, Reconceptualizing Organizational Routines as a Source of Flexibility and Change, Administrative Science Quarterly, 48(1), 2003, pp. 94-118.

[10] Fernandez, W.D., The Grounded Theory Method and Case Study Data in IS Research: Issue and Design. Information Systems Foundations: Constructing and Criticising, ed. D.N. Hart and S.D. Gregor, Vol. 1, ACT, Australia: ANU E Press, 2004.

[11] Glaser, B.G., Theoretical Sensitivity: Advances in the Methodology fo Grounded Theory: Sociology Press, 1978.

[12] Glaser, B.G., Doing Grounded Theory: Issues and Discussions: Sociology Press, 1998.

[13] Glaser, B.G. and A.L. Strauss, The Discovery of Grounded Theory, Chicago: Aldine, 1967.

[14] Goitein, L. and B. James, Standardized Best Practices and Individual Craft-Based Medicine: A Conversation about Quality, JAMA Internal Medicine, 176(6), 2016, pp. 835-838.

[15] Jasperson, J., P.E. Carter, and R.W. Zmud, A Comprehensive Conceptualization of the Post-Adoptive Behaviors Associated with IT-Enabled Work Systems, MIS Quarterly, 29(3), 2005, pp. 25-57.

[16] Jones, S.S., R.S. Rudin, T. Perry, and P.G. Shekelle, Health Information Technology: An Updated Systematic Review with a Focus on Meaningful Use, Annals of Internal Medicine, 160(1), 2014, pp. 48-54.

[17] Kent, W., Data and Reality: 1st Books Library (originally published by North Holland, 1978), 2000.

[18] Kuhn, T., P. Basch, M. Barr, and T. Yackel, Clinical Documentation in the 21st Century: Executive Summary of a Policy Position Paper from the American College of Physicians, Annals of Internal Medicine, 162(4), 2015, pp. 301-303.

[19] Lauterbach, J., F. Kahrau, B. Mueller, and A. Maedche, What Makes "The System" Tick? Explaining Individuals' Adaptation Behavior towards Effective Use in Enterprise System Implementations, in Proceedings of the 35th International Conference on Information Systems: Auckland, NZ, 2014, p. 1-21.

[20] Leonardi, P.M., When Does Technology Use Enable Network Change in Organizations? A Comparative Study of Feature Use and Shared Affordances, MIS Quarterly, 37(3), 2013, pp. 749-775.

[21] Parsons, J. and Y. Wand, Emancipating Instances from the Tyranny of Classes in Information Modeling, ACM Transactions on Database Systems, 25(2), 2000, pp. 228268.

[22] Poole, M.S. and A.H. Van de Ven, Using Paradox to Build Management and Organization Theories, Academy of Management Review, 14(4), 1989, pp. 562-578.

[23] Robinson, K. and J. Shepheard, Predicting the Influence of the Electronic Health Record on Clinical
Coding Practice in Hospitals, Health Information Management, 32(3-4), 2004.

[24] Sandelowski, M., Real Qualitative Researchers do not Count: The Use of Numbers in Qualitative Research, Research in Nursing \& Health, 24(3), 2001, pp. 230-240.

[25] Simborg, D.W., Promoting Electronic Health Record Adoption. Is it the Correct Focus, Journal of the American Medical Informatics Association, 15(2), 2008, pp. 127-129. [26] Slight, S.P., et al., Meaningful Use of Electronic Health Records: Experiences from the Field and Future Opportunities, JMIR Medical Informatics, 3(3), 2015, pp. e30.

[27] Spee, P., P. Jarzabkowski, and M. Smets, The Influence of Routine Interdependence and Skillful Accomplishment on the Coordination of Standardizing and Customizing, Organization Science, 27(3), 2016, pp. 759781.

[28] Stein, M.-K., E.T. Lim, and C.-W. Tan, Tensions to Frictions? Exploring Sources of Ineffectiveness in MultiLevel IT Use in Proceedings of the 35th International Conference on Information Systems: Auckland, 2014, p. 110.

[29] Strong, D.M., Y.W. Lee, and R.Y. Wang, Data Quality in Context, Communications of the ACM, 40(8), 1997, pp. 103-110.

[30] Strong, D.M. and O. Volkoff, Understanding Organization-Enterprise System Fit: A Path to Theorizing the Information Technology Artifact, MIS Quarterly, 34(4), 2010, pp. 731-756.

[31] Strong, D.M., et al., A Theory of Organization-EHR Affordance Actualization, Journal of the Association for Information Systems, 15(2), 2014, pp. 53-85.

[32] van Offenbeek, M., A. Boonstra, and D. Seo, Towards Integrating Acceptance and Resistance Research: Evidence from a Telecare Case Study, European Journal of Information Systems, 22, 2013, pp. 434-454.

[33] Venkatesh, V. and H. Bala, Technology Acceptance Model 3 and a Research Agenda on Interventions, Decision Sciences, 39(2), 2008, pp. 273-315.

[34] Wang, N., D. Hailey, and P. Yu, Quality of Nursing Documentation and Approaches to its Evaluation: A Mixed-Method Systematic Review, Journal of Advanced Nursing, 67(9), 2011, pp. 1858-1875.

[35] Wang, R.Y. and D.M. Strong, Beyond Accuracy: What Data Quality Means to Data Consumers, Journal of Management Information Systems, 12(4), 1996, pp. 5-33.

[36] Wears, R.L., Standardisation and its Discontents, Cognition, Technology, and Work, 17, 2015, pp. 89-94.

[37] Zierler-Brown, S., T.R. Brown, D. Chen, and R.W. Blackburn, Clinical Documentation for Patient Care: Models, Concepts, and Liability Considerations for Pharmacists, American Journal of Health-System Pharmacy, 64(17), 2007, pp. 1851-1858.

\section{Appendix}

Appendix 1: Consequences of inconsistency

\begin{tabular}{|l|l|l|l|}
\hline $\begin{array}{c}\text { Inconsistency } \\
\text { Type }\end{array}$ & Consequence & $\begin{array}{l}\text { Variation in } \\
\text { Instances }\end{array}$ & \multicolumn{1}{c|}{ Example Quotes } \\
\hline $\begin{array}{l}\text { Inconsistency } \\
\text { in Process }\end{array}$ & Collaboration & $\begin{array}{l}\text { Specific } \\
\text { ineffective }\end{array}$ & $\begin{array}{l}\text { A surgeon has refused to [use the EMR] and writes her notes on } \\
\text { pieces of paper, so the nurses are running around grabbing it and }\end{array}$ \\
\hline
\end{tabular}




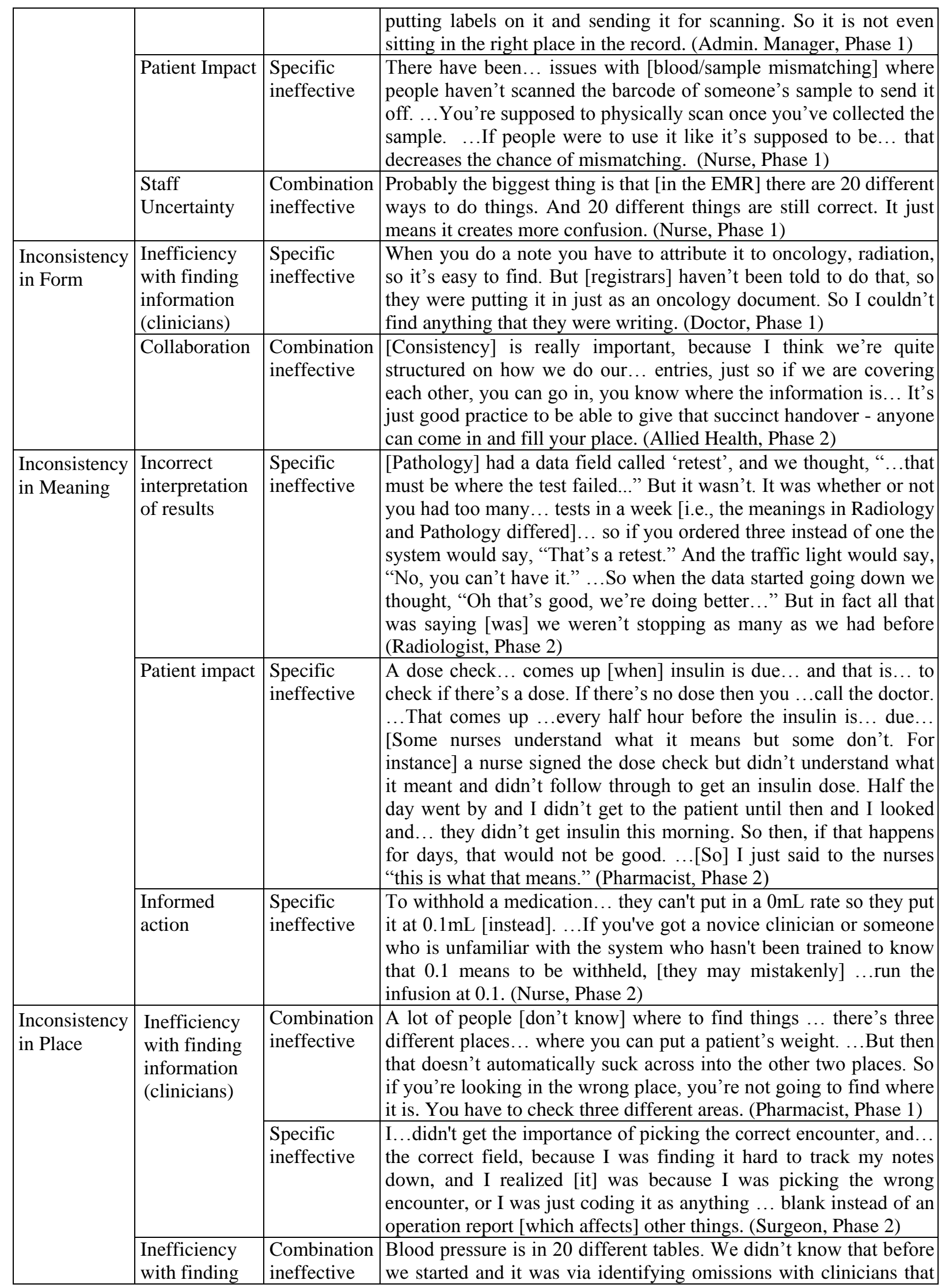




\begin{tabular}{|c|c|c|c|}
\hline & \begin{tabular}{|l} 
information \\
(management)
\end{tabular} & & $\begin{array}{l}\text { were able to work out we were missing lying and standing blood } \\
\text { pressures, or [those] done in clinics... It's just a really difficult } \\
\text { process that we have learnt how to work with. (Manager, Phase 2) }\end{array}$ \\
\hline & $\begin{array}{l}\text { Informed } \\
\text { Action }\end{array}$ & \begin{tabular}{|l|} 
Combination \\
ineffective
\end{tabular} & $\begin{array}{l}\text { [We need to] make sure people are actually checking ...the various } \\
\text { risk assessments and acting on them because they may not... be in a } \\
\text { place right in front of them. (Senior Executive, Phase 1) }\end{array}$ \\
\hline & Collaboration & $\begin{array}{l}\text { Specific } \\
\text { ineffective }\end{array}$ & $\begin{array}{l}\text { The EMR has a function of orders [for referrals].... But I'm seeing } \\
\text { doctor's note [in the progress note, not in the orders] from } \\
\text { yesterday, and he's written "physio chest please"... Nobody [not a } \\
\text { clinician nor the orders in the EMR] told me that, but I'm } \\
\text { responding to that. (Allied Health, Phase 1) }\end{array}$ \\
\hline & \begin{tabular}{|l} 
Decision \\
Support
\end{tabular} & $\begin{array}{l}\text { Specific } \\
\text { ineffective }\end{array}$ & $\begin{array}{l}\text { So if you're taking a history, [patient] is allergic to penicillin... and } \\
\text { the doctor writes it as he's writing his normal note like... and } \\
\text { doesn't stick it up in the allergy section then we've missed that } \\
\text { opportunity for clinical decision support. (Radiologist, Phase 2) }\end{array}$ \\
\hline \multirow[t]{6}{*}{$\begin{array}{l}\text { Inconsistency } \\
\text { in Content }\end{array}$} & \multirow[t]{2}{*}{$\begin{array}{l}\text { Informed } \\
\text { Action }\end{array}$} & \begin{tabular}{|l|}
$\begin{array}{l}\text { Combination } \\
\text { ineffective }\end{array}$ \\
\end{tabular} & $\begin{array}{l}\text { It's not always visible, so you don't know it's been done, and so we } \\
\text { might get some duplicates. I might think that that person hasn't had } \\
\text { their blood and they have. So, some things pull through ... onto the } \\
\text { fluid balance chart, for example, but it might not tell you that it was } \\
\text { blood, it might just say that it was a litre of fluid, unless you've } \\
\text { documented in a certain way (Director of Nursing, Phase 1) }\end{array}$ \\
\hline & & \begin{tabular}{|l|} 
Specific \\
ineffective
\end{tabular} & $\begin{array}{l}\text { So [the residents] put in [their] temporary notes which usually is a } \\
\text { cut and paste of yesterday's [with] a little space down ... where they } \\
\text { can add in [content]. Then they come back later fix it up [and] put it } \\
\text { all in. ... We have had some occurrences where that was supposed to } \\
\text { be awaiting finalization but the physio's seen that information and } \\
\text { gone, okay, so I can start. (Allied Health, Phase 1) }\end{array}$ \\
\hline & Collaboration & $\begin{array}{l}\text { Specific } \\
\text { ineffective }\end{array}$ & $\begin{array}{l}\text { Some doses were missing. ... There's no one medication that they're } \\
\text { missing. A lot of times we're chasing Warfarin. Usually we give } \\
\text { Warfarin at } 4: 00 \text { pm. ...Yesterday ...I paged these doctors, I had two } \\
\text { Warfarin doses that I needed and I paged them about four or five } \\
\text { times. Please chart this Warfarin. It needs to be given at the same } \\
\text { time every day. (Nurse, Phase 1) }\end{array}$ \\
\hline & Patient Impact & $\begin{array}{l}\text { Specific } \\
\text { ineffective }\end{array}$ & $\begin{array}{l}\text { So [the nurses] would not do the searches correctly, [e.g. incorrect } \\
\text { date of birth or spelling] so that has caused massive patient } \\
\text { identification issues. ...Duplicates... we were getting at least five a } \\
\text { day. Overwrites are happening [and] are really serious [and is } \\
\text { where]... they've confused patient one with patient two [and] } \\
\text { copied patient two's details over ... patient one... A patient's } \\
\text { information is now incorrect and blood types could be [incorrect] } \\
\text { the implications are really serious. (Admin. Manager, Phase 1) }\end{array}$ \\
\hline & $\begin{array}{l}\text { Continuity of } \\
\text { Care }\end{array}$ & $\begin{array}{l}\text { Specific } \\
\text { ineffective }\end{array}$ & $\begin{array}{l}\text { The discharge reconciliation is when [the doctors] say what } \\
\text { [medications are] to continue, what is to stop on a discharge form } \\
\text { [and] what is charted to going home. They obviously weren't taught } \\
\text { how to do that process ... like it [e.g. the content] was very wrong. } \\
\text {...Everything was just continuing, and the wrong dose. ... It was just } \\
\text { a nightmare. (Pharmacist, Phase 2) }\end{array}$ \\
\hline & $\begin{array}{l}\text { Inefficiency } \\
\text { with finding } \\
\text { information } \\
\text { (Management) }\end{array}$ & $\begin{array}{l}\text { Specific } \\
\text { ineffective }\end{array}$ & $\begin{array}{l}\text { If they're looking at falls, or... pressure injuries... and they were } \\
\text { trying to pull that data... it could be used for that. But again, that's } \\
\text { actually one of the areas that again is missed all the time now, as } \\
\text { [some] people are not doing [the documentation]. You can see a } \\
\text { patient here for two weeks who hasn't had a skin assessment } \\
\text { documented, because it just hasn't been done....[So] I'm not } 100 \% \\
\text { convinced that it would be useful [to pull the data], it wouldn't } \\
\text { show everything; it's not complete. (Nurse, Phase 1) }\end{array}$ \\
\hline
\end{tabular}

